\title{
De la Historia moral a la Historia civil en el Compendio de la Historia Civil del Reyno de Chile (1787) del abate Juan Ignacio Molina
}

\author{
Dr. Luis Hachim Lara* \\ Universidad de Santiago de Chile
}

\begin{abstract}
Resumen:
El jesuita Juan Ignacio Molina escribió el Compendio de la Historia Geográfica, Natural y Civil del Reyno de Chile (1776) y el Compendio de la Historia Civil del Reyno de Chile (1787) en el exilio italiano. En los estudios sobre los jesuitas, sus Historias naturales no han sido exploradas en cuanto a la importancia cultural, literaria y crítica que implican. En este trabajo se tratarán algunos rasgos de la escritura de la Historia que constituyen el discurso de la ciencia y que muestran el desarrollo que va desde la Historia natural y moral -que desde Aristóteles y Plinio representa la ciencia clásica- a los nuevos modos de conocer que representa el modelo de ciencia de la llustración. En consecuencia, el aporte del Abate Molina en su Compendio de la Historia Civil consiste en incorporar la concepción de progreso en los usos y costumbres de los indígenas, aportando una visión de integración diferente a la civilidad. Sabemos que con posterioridad al siglo dieciocho el aporte de muchos astrónomos, médicos y científicos jesuitas -en América- construyeron las bases de la ciencia moderna y progresiva, representando la continuidad más que la regresión en el desarrollo científico tal como lo concebimos actualmente.
\end{abstract}

Palabras clave: estudios coloniales, llustración hispanoamericana, pensamiento crítico y literario latinoamericano

\begin{abstract}
:
The Jesuit Juan Ignacio Molina wrote the Compendio de la Historia Geográfica, natural y Civil del Reyno de Chile (1776) y el Compendio de la Historia Civil del Reyno de Chile (1787) in exile in Italy. In relation to criticism, the thinking of the naturalist of the company in the transition -some see opposition-from the model of traditional and scholastic science to the paradigm of modern and enlightened science was important. This assignment will consider some of the characteristics of the writing of history, which constitute the discourse of science and show the development from the moral and natural history -the classical science of Aristotle and Plinio- to the new forms of knowledge that represent the model of science of the enlightenment. Both in natural history and civil history, the scientific practice of Molina transcends the duality scholastic science/enlightened science. We know that post eighteenth century, the contribution of many astronomers, doctors and Jesuit scientist -in the Americas- built the basis of modern and progressive science, representing the continuity rather than the regression in scientific development such as we considerer it today
\end{abstract}

Key words: Colonial Studies, Spanish-American Enlightenment, Latin American Critical and Literary Thought

Este trabajo se inscribe en el Proyecto Fondecyt 1060142 La llustración hispanoamericana: El siglo XVIII en Chile y el área andina. Una primera versión fue expuesta en JALLA2006, Bogotá (Colombia). Dr. Luis Hachim, Facultad de Humanidades Universidad de Santiago de Chile. luis.hachim@usach.cl 


\section{Introducción}

En los estudios coloniales actuales ha aumentado el interés por las Historias Naturales. En la larga tradición de los textos que cumplieron con difundir "la ciencia" de la época, la forma que narra el cosmos, la geografía, botánica, mineralogía y al hombre, se estabiliza formalmente con Plinio (23 - 27 DC) y su Naturalis Historia. Las sucesivas variantes del libro naturalista, a pesar de todo, van configurando un texto predominantemente narrativo, que produce un conocimiento que desde la antigüedad sirvió para dar cuenta de los reinos de la naturaleza: mineral, vegetal y animal. Este último reino incluía al hombre, sin embargo, de a poco el estudio del hombre y sus costumbres - mores- deriva en una especie de antropología que va a dar cuenta de las costumbres humanas en su etapa de desarrollo civil (occidental). Ese saber sufre una crisis epistémica con la aparición de América. El Nuevo mundo con otra geografía y otra humanidad, especies botánicas y minerales desconocidas, tiene que ser nuevamente incorporado a los archivos. Así las Historias Naturales en América cumplirán el proyecto imperial de catalogar las nuevas propiedades (posesión y cualidades). Se trata de territorializar el Nuevo mundo a través de la ekfrasis. El texto cuya narrativa suministró nuevos conocimientos al imperio, se enfrenta ahora al examen de la razón llustrada. La narración tiene que ser legitimada por la racionalidad científica. En ese contexto racionalista e llustrado, irrumpen los letrados hispanoamericanos expulsos, produciéndose la polémica de Indias. En este caso, los jesuitas criollos, discuten y cuestionan el conocimiento de los Filósofos de salón y corrigen sus errores, sobre la naturaleza americana y sus habitantes. La narración naturalista de Molina trasciende la ekfrasis, mediante la autopsia (verse a sí mismo) dando paso a esas narraciones en que los sujetos se implican en el objeto. Estos letrados hablan nahuatl, quechua, mapudungun. A pesar del grado cero de sus plataformas de ciencia, introducen el conflicto en el saber occidental. En función de ver estos problemas, corresponde establecer la procedencia de estas historias. 


\section{Historias naturales}

La naturalis historia cuya procedencia en la antigüedad se relaciona con los textos fundadores de Estrabón (63 a. de C) y sus Memorias históricas, la Historia de Heródoto (444 a. de C), Filosofía de la naturaleza de Aristóteles (384-322 a. C), Enciclopedia de Varrón (116-27 a. C.) la Historia natural de Plinio (23-27 d. C.) y San Isidoro con sus Etimologías'. En estas obras precursoras, la Literatura se desarrolló como una narración² sobre el conocimiento en la que "se moldeará el género de la 'historia natural, que alcanzará su máximo desarrollo durante el siglo XVIII" (Asúa 27). Así la mayoría de las Historias Naturales posteriores, siguen el uso asentado por Plinio de una estructura ternaria: prefacio, dedicatoria e índices. Aun más, muchos autores continuarán aplicando la taxonomía con que éste distribuyó las especies en sus treinta y siete libros ${ }^{3}$ :

"La Historia Natural (...) es, pues, no solo un monumento de lo que los romanos del siglo I d. C. consideraban como «la ciencia» [...], sino también un tesoro de documentación" humana ${ }^{4}$. Incluso, en el siglo 17, la Historia Natural se seguía entendiendo como "disciplina afín a las ciencias de la naturaleza"5 pero bajo la tutela de la Literatura.

Es difícil saber si en ese momento, -junto al conocimiento difundido por el verbo narrar-, los letrados se sirvieron de las historias naturales para tratar con otras facultades del conocimiento o examinar incluso su relación con otros géneros considerados vulgares. Lo cierto es, que entre esas noticias naturales y enciclopédicas se encuentran observacio-

Para una útil revisión, véase: "América en el nacimiento de la geografía moderna. O sea, de las crónicas medievales a las crónicas de Indias pasando por Plinio y el descubrimiento de las tierras nuevas". Horacio Capel: Suplementos Anthropos/43. La geografía hoy (Barcelona), 43 (1994): 42-51.

2 Considero performativamente el verbo "narrar" como el acto comunicativo básico del pensamiento, determinado por su referente, el enunciado en prosa narrativa y por su relación de sentido con el proceso de enunciación. Probablemente aquí la acepción de relato en versión post moderna, resultaría anacrónica. Sin embargo, la categoría "narratividad" -ya expuesta por Ricoeur (1980) y por Hayden White- es parte del instrumental conceptual del especialista en estudios coloniales.

3 Los libros están organizados según esta tabla: Libro 1. Prefacio (dedicatoria) e índices. 1-2 El cosmos. 3-6 Geografía. 7 [Figuras admirables de gentes]. 8-11 Reino animal. 12-19 Reino vegetal. 20-27 Farmacopea vegetal. 28-32 Farmacopea animal. 33-37 Reino mineral. Cf. Cayo Plinio Segundo: Historia Natural. México:Visor, 1999. Igualmente, Plinio El viejo: Historia Natural [Libros VII-XI] Madrid: Gredos, 2003. En la primera nota los traductores agregan: "En la fase final de la elaboración de los libros VII-XI hemos tenido conocimiento de la reciente publicación de la Historia Natural, traducida por J. Cantó et alii, Cátedra, Madrid 2002, de lo cual queremos dejar constancia en esta primera nota" 7.

4 Guy Sebat: "Introducción general". Plinio El Viejo: Historia Natural. Madrid: Gredos, 1995: 9.

5 Santiago Montero Díaz: "La doctrina de la historia en los tratadistas españoles del siglo de oro". Hispania (Revista española de Historia), (Madrid), IV, (1941): 2 -39. 
nes sobre la historia moral, referida a las costumbres del hombre en su primera etapa primitiva o estado natural que Hobbes opone al "estado civil" de cultura. En su estudio de la filosofía antigua, Hegel postula que en los sofistas la "palabra 'cultura' es [era], ciertamente, una palabra un tanto vaga". Pero ya se entendía la construcción de la cultura -acto distintivo de lo humano- como resultado del "pensamiento libre [que de acuerdo a] su propia convicción; no [...] trata de creer sino de indagar" (Hegel 12). El mismo concluye que: "la cultura es, en una palabra, lo que en los tiempos modernos se llama ilustración" (12). A ese conjunto de prácticas y relatos acumulados en términos de cultura, contribuyó en gran medida la Naturalis historia a cuya consolidación como género, contribuyeron los pensadores anteriormente nombrados, sobre todo Sócrates, Platón y Aristóteles. Éste último, desde el marco de la ya citada Filosofía de la Naturaleza escribió varios libros: Teoría física, Metereología, Sobre el universo. Libros sobre la naturaleza orgánica y posteriormente la historia natural que contiene una Historia de los animales y otro Sobre las plantas (Hegel 270-271).

En esta tradición de la cultura clásica, se inscribe el saber Occidental y consecuentemente la actividad científica de los letrados que llegaron a América En esa etapa y en perspectiva de circunscribir el tema a las Historias Naturales en América, corresponderían algunas observaciones respecto a la llegada de los españoles a las Indias, Nuevo Mundo y América. Este acontecer produce cambios significativos en la ecúmene clásica -Europa en la cúspide, África y Asia en la base-, que desde el punto de vista del conocimiento, entra en crisis con la aparición de América. Esta crisis (epistémica) es parte del desarrollo de los dispositivos de saber ${ }^{6}$ que estamos tratando.

En el periodo de las Indias (1492) del Nuevo Mundo (1503) y de América a partir de 1507, el desarrollo de las historias naturales cumple servicios inapreciables al poder español. En esta dimensión, es pionera la narrativa naturalista de Gonzalo Fernández de Oviedo:

La polimórfica Historia general y natural de las Indias de Fernández de Oviedo es, ante todo, la primera historia natural del nuevo continente; pero es también la primera defensa sostenida de la expansiva Monarquía Católica, el mayor imperio en términos geográficos, si no poblacionales, que

6 En el año 2003 en Latin American Studies Association LASA, Dallas, Texas, March 27-29, presenté la ponencia "Sujeto y proyecto ilustrado en el Compendio de la Historia Geográfica, Natural y Civil del Reyno de Chile (1776) del abate Juan Ignacio Molina". Este trabajo con las Historias Naturales de los jesuitas, se vio complementado con la publicación de Luis Millones y Domingo Ledesma [eds.] El saber de los jesuitas, historias naturales y el Nuevo Mundo. Madrid: Vervuert/Iberoamericana, 2005. 
el mundo nunca antes hubiera conocido y que no volviera a conocer hasta el siglo XIX. (Presentación de Anthony Padgen al ensayo de Jesús Ma Carrillo: 12) ${ }^{7}$.

Esta Historia General y Natural escrita por el cronista español y encomendero Fernández de Oviedo en $1535^{\circ}$, revela un conjunto de características adecuadas al proyecto de la Corona:

Según se pretendía de la historiografía oficial, la eliminación de toda huella de intervención personal en la narrativa del Cronista Real le convertía en el vehículo efectivo de la verdad. Los hechos de la realeza estaban sostenidos $a$ priori por una trama subyacente, un discurso ideológico que soportaba su valor de verdad, que el historiador había de trasladar como un espejo a su texto (Carrillo 40).

Igualmente importante para el conocimiento de las nuevas realidades, es que:

[El] respeto táctico por lo autóctono no debe ocultar el hecho de que el gesto globalizador de comprender y organizar la diversidad territorial y lingüística en una obra como la de Oviedo responde básicamente, a una dinámica imperialista donde el conocimiento de lo local es sólo un paso hacia su dominación. Los nombres acuñados por los soldados y colonos españoles, que Oviedo recoge al lado de las variedades nominales nativas, aparecen siendo el rastro de ese proceso de territorialización, que es la expansión imperial en América. Estos nombres son las huellas de una violencia ejercida sobre lo dado, sobre la diferencia local que Oviedo registra (Carrillo 150).

En esta primera fase las Historias Naturales clásicas, se caracterizaron por ser un modelo puramente referencial, en cambio en Oviedo la Historia general y natural de las Indias se constituye como un modelo comunicacional o retórico, que se caracteriza por un particular estilo descriptivo, centrado en la ékfrasis:

$7 \quad$ Anthony Padgen: "Presentación”. En Jesús Ma Carrillo Castillo: Naturaleza e imperio. La representación del mundo natural en la Historia general y natural de las Indias de Gonzalo Fernández de Oviedo. Madrid: Doce Calles, 2004: 12.

8 Gonzalo Fernández de Oviedo escribe antes el Sumario de la Natural Historia de las Indias (año 1526) en la Dedicatoria a su Real Majestad, manifiesta su admiración por "Plinio, el cual, mejor que otro autor en lo que toca a la natural historia [...] escribió [...] imitando al mismo, quiero yo. Gonzalo Fernández de Oviedo: Sumario de la Natural Historia de las Indias. Madrid: DASTIN, 2002: 55. 
Una descripción detallada que se torna visible, es decir, que trae ante los ojos aquello que se muestra. Puede haber ékfrasis de gente, de hechos, de tiempos, lugares, estaciones y muchas otras cosas [...] La virtud especial de la ékfrasis es su claridad y visibilidad; el estilo debe esforzarse en provocar la visión a partir de la audición. Sin embargo, es igualmente importante que la expresión se adecue al tema (Jesús Ma Carrillo 206).

En la etapa de cultura del Nuevo Mundo se hace visible -a través del texto naturalista grafológico e icónico, que da cuenta del "ente geográfico" y "humano"- lo que el europeo está viendo, para esto los cronistas introducen un control del sentido orientado al lector, en este caso el Rey, la corte y funcionarios del poder español.

\begin{abstract}
Las imágenes que ilustran las descripciones de las especies naturales americanas contenidas en la Historia general y natural eran una completa novedad, tanto en el contexto de la literatura botánica ibérica, como en el de los textos contemporáneos acerca del Nuevo Mundo. De hecho, la obra de Oviedo es la primera historia natural ilustrada impresa en España y también el primer conjunto de imágenes de la fauna y la flora americana en ser publicado en Europa (Carrillo 243).
\end{abstract}

Sesenta y siete años después el jesuita español José de Acosta registra su propia experiencia botánica, zoológica y moral -como fruto de sus estadías en Perú, México y Santo Domingo- en la Historia Natural y Moral de las Indias (1590) cuya información es esencial para entender las costumbres de los nuevos "sujetos" e involucrarlos en la cristiandad. Su historia recoge preciadas "noticias" acerca de una flora y una fauna desconocida, junto con abordar la Historia moral de los incas. John Locke postula que los americanos todavía se encuentran en la etapa natural, no sujetos a los beneficios de la organización civil "Y si José Acosta ha de merecernos crédito, por él sabremos no haber existido en muchas partes de América gobierno alguno" (Segundo ensayo 66) Sobre el título del libro Historia natural y moral de las Indias; en el siglo dieciséis los investigadores reseñan el uso estable de la palabra moral que implica su relación con el latín mos, mores aludiendo a costumbre, junto a la palabra historia con un significado de indagación o investigación (Howland Rowe "Ethnography" 1). La Historia moral de Acosta, a grandes rasgos contiene una primera parte referida al universo, la tierra y al Nuevo Mundo y los tres reinos; mineral, vegetal y animal. La segunda, trata la Historia Moral, referida a las costumbres y hechos de los indios (José de Acosta Historia natural) y que correspondería a Figuras admirables de gente o Antropología en 
Plinio. El investigador Fermín del Pino junto con exponer reflexiones sustanciales sobre la Historia de Acosta, privilegia el carácter literario de ésta, incluyendo sin conflictos la narrativa científica del jesuita:

Por lo que sabemos a ciencia cierta, la distinción expresa entre historia natural y moral no se hace hasta las "Ordenanzas para la formación del libro de las descripciones de Indias", decretadas por Felipe II en 1573, que dan lugar al famoso cuestionario de 50 preguntas del 77, obra de López de Velasco: el autor mismo de la Geografía y Descripción Universal de las Indias, y también coordinador de las famosas Relaciones Geográficas de Indias, publicadas luego por Jiménez de la Espada desde $1881^{9}$.

El jesuita Acosta desarrolla eficientemente la narrativa del gesta Dei en su Historia moral, en la que es apreciable la conexión con el género misional que los letrados de la orden estaban difundiendo en todos los lugares en que evangelizaban, construyendo así una versión propia del peregrino, del aventurero de Cristo o del viajero que investiga y que a través de las historias, representa la vida de otros pueblos, la moral de aquellos que, pese a su alteridad pueden ser incorporados al proyecto divino.

Lo que casi siempre hacían los jesuitas inmersos en un entorno ajeno era describir. No como lo harían unos etnólogos de hoy, amparándose en paradigmas y teorías, sino describiendo sin más. Lo hacían porque sentían la curiosidad, ciertamente-muchos jesuitas figuraban entre los científicos más destacados de su época-, pero también porque la descripción era una función necesaria en orden a la salvación de almas. Describir una sociedad -y hacerlo en todas sus dimensiones-, era evaluar su potencial espiritual, su capacidad inherente para recibir el Evangelio (Wright 96-97).

Correlativamente, la necesidad de conocer implicaba una epistemología característica del estado de ciencia en que se encontraba el saber de este jesuita español. En su clasificación de las ciencias, Bacon (año 1605) coloca las Historia naturales bajo la facultad de la memoria ${ }^{10}$, en

$9 \quad$ Fermín del Pino: “La Historia Natural y Moral de las Indias como género: orden y génesis literaria de la obra de Acosta. http://www.fas.harvard.edu/ icop/fermindelpino.html. 11.08.06.

10 Oviedo enfatiza en su Dedicatoria del Sumario la facultad de la memoria "ni hay de esta escritura más de lo que en la memoria está y puedo de ella aquí recoger" en G. Fernández de Oviedo: Sumario de la Natural Historia de las Indias. Madrid: DASTIN, 2002: 56. 
sus variantes naturales y/o civiles. En el siglo dieciocho, en la Enciclopedia, Diderot y D'Alembert al transformar el árbol del conocimiento,-definiendo la facultad de la razón como centro de la taxonomía-, establecen que el Conocimiento de la Naturaleza se constituye en relación con la rama de la Filosofía Natural ${ }^{11}$ pero, mantienen bajo la facultad de la memoria las narrativas de las Historias (naturales y civiles). La práctica científica de los jesuitas ilustrados se relaciona con el dispositivo de la noticia narrativa que constituye la Historia Natural. En el modelo llustrado de Ciencia, que ya sufre cambios importantes, la Historia Natural continúa definiéndose como una narración, es decir, como una actividad literaria que el también jesuita Juan Andrés, caracterizó en su obra Origen, progresos y estado actual de toda la literatura. [1784]. En esta obra dedicada al Ilustrado Joseph Moñino, Conde de Florida-Blanca, el sacerdote incluye los conocimientos geográficos, naturales, matemáticos, zoológicos y culturales bajo el patrocinio de la Literatura ${ }^{12}$. En igual medida se debe entender -en la tradición letrada de los jesuitas-, la Ratio Studiorum, que más allá de su carácter preceptivo, supone un método de aproximación a los objetos de estudio, los fenómenos naturales y los grupos humanos, llegando a coincidir con las propuestas ilustradas en el espacio geográfico hispanoamericano ${ }^{13}$.

En perspectiva de un estudio de la actividad científica de la Compañía de Jesús, éste no puede obviar las investigaciones y discusiones científicas del jesuita mexicano Francisco Javier Clavijero, de los ex jesuitas chilenos Juan Ignacio Molina y Manuel Lacunza y del padre riobambeño Juan de Velasco ${ }^{14}$.

Algo que con frecuencia se olvida cuando se habla de la introducción de la filosofía moderna en México [y en América meridional] es la intención de base que tuvieron la mayor parte de sus receptores, como es el mismo Clavijero, de no acabar con lo anterior, sino de revitalizar,

11 Robert Darnton: “Los filósofos podan el árbol del conocimiento". La gran matanza de gatos y otros episodios en la historia de la cultura francesa. México: Fondo de Cultura Económica, 19872: 192-216.

12 Abate Juan Andres: Origen, progresos y estado actual de toda la literatura. [Primera edición] Madrid: Antonio de Sancha, 1784, Prólogo.

13 La acción educativa, económica y científica de los jesuitas debe ser juzgada de acuerdo a los contextos en que se ocurre. No es lo mismo examinar el jesuitismo en Francia, Portugal, España que en América. Cfr. Herman Shwember: Las expulsiones de los jesuitas. Santiago de Chile: J. C. Sáez, 2004.

14 Lo mismo puede decirse del médico quiteño Eugenio de Santa Cruz y Espejo en la reflexión médica y de crítica al sistema colonial y también del ex jesuita peruano Juan Pablo Viscardo y Guzmán y su producción sobre la emancipación americana. Cf. Luis Hachim Lara: Tres estudios sobre el pensamiento crítico de la llustración americana. Alicante: Universidad de Alicante y Universidad de Santiago, 2000. 
perfeccionar y mejorar lo antiguo con lo nuevo. Tal es el sentido de un eclecticismo sano. Clavijero se muestra en este sentido ecléctico, tratando de sintetizar el pensamiento aristotélico-escolástico con el moderno. Es una actitud conciliadora y no destructiva de la filosofía escolástica en aras de la moderna ${ }^{15}$.

[Charles Ronan, autor de un estudio sobre Clavijero, dice que éste se ubica dentro de] una filosofía cristiana de la historia. Este autor halla en las obras históricas de Clavijero la aserción decidida de que Dios interviene en la acción del hombre y en toda la historia. Esta intervención de Dios tiene cuatro modalidades: a) es la explicación última y más profunda del devenir de la historia; b) dirige las vicisitudes de los hombres de una manera metafísica, sin disminuir la libertad de estos; c) conduce la historia al cumplimiento de determinados fines divinos - planes de la providencia-y d) permite la intervención del mal-como algo que introduce imperfección o límite en la historia humana-. Y es que, por la subordinación que tienen a Dios, los males llegan a producir bienes para el hombre (Mauricio Beuchot: obra citada: 240-241).

El aporte científico e histórico de los jesuitas expulsos al conocimiento de América es fundamental. Ellos, en el exilio italiano, discutieron desde la alteridad con el saber europeo hegemónico. Antonello Gerbi registra en La disputa del Nuevo Mundo, el valor de estos jesuitas, especialmente de Clavijero (Historia antigua de México) 1780, de Juan de Velasco (Historia del reino de Quito en la América meridional) 1789 y también del Abate Molina con su Compendio de una Historia Geográfica, Natural y Civil del Reyno de Chile de $1776^{16}$ y el Compendio de la Historia Civil del Reyno de Chile escrito en el año $1787^{17}$.

15 Mauricio Beuchot: Historia de la filosofía en el México Colonial. Barcelona: Herder, 1996: 232

16 Juan Ignacio Molina: Compendio della storia geografica, naturale e civile del regno del Chile se publicó en Bolonia el año 1776, sin el nombre del verdadero autor, es decir del jesuita chileno exiliado Juan Ignacio Molina. Por esta razón fue atribuida erróneamente a otro jesuita chileno, Felipe Gómez de Vidaurre.

17 El título completo de esta primera edición italiana en octavo mayor [12x19] es Saggio sulla Storia Civile del Chili del Signor Abate Giovanni Ignazio Molina. Bologna: Nella Stamperìa di S. Tommaso d' Aquino. Con licenza de' Superiori, MDCCLXXXVII. Esta no difiere significativamente de la edición española de 1795, sin embargo contiene un mapa una "Carta del paese, che abitano gli araucani nel Chili de poncio chileno" que no figura en la traducción de Nicolás de la Cruz y Bahamonde. 
Lo que Velasco escribió en el exilio de Faenza en el 1789, según Gerbi "desenmascaraba a De Paw, Robertson, Raynal, Marmontel y Bufón, autores de escritos brillantes y engañosos bajo cuya influencia -dice Velasco- ha llegado a formarse 'una moderna secta de filósofos antiamericanos' [Gerbi transcribe las palabras del padre Velasco]" ${ }^{\prime 18}$. Incluso los tres sacerdotes -ex jesuitas de acuerdo al decreto de extinción-, desarrollan una peculiar reflexión sobre los perros, registradas en sus respectivas Historias. El padre Velasco escribe:

Allcu era el nombre que daban los indianos a una especie de perro doméstico que tenían y fue sin duda el que dio la especie al señor Paw, para que dijese que todos los perros en América eran mudos (Ibídem: 183)

Molina a su vez, también se refiere a éstos en sus noticias zoológicas:

En cuanto á los perros, no es mi animo establecer que todas las razas conocidas actualmente en el Reino de Chile se encontrasen allí antes que entrasen los Españoles; pues únicamente sospecho que antes de aquella época existiese allí el Borbón pequeño llamado Kiltho, y el Thegua ó perro común, los cuales han sido encontrados en todas las tierras que se han descubierto hasta el Cabo de Hornos. Es verdad que estos perros ladran como los originarios de Europa: mas no por esto deben ser reputados como extranjeros, mediante á que la opinión de ser mudos los perros americanos, únicamente provino del abuso que cometieron los primeros conquistadores aplicando, según su antojo, y sin verdadero discernimiento los nombres de las cosas del mundo antiguo á los nuevos objetos que les presentaban alguna leve apariencia de semejanza ó conformidad con los que habían dejado en Europa. Así fue, como habiendo encontrado en México el Techichi, animal mudo y algo parecido al perro, aunque de genero muy distinto, cual lo manifiesta el Abate Don Francisco Xavier Clavijero en su erudita historia de México, les bastó esta leve apariencia para creer que fuese un verdadero perro, y para darle este nombre; tomando de aquí motivo para contar entre las demás cosas extraordinarias que aseguraban haber encontrado en América, el que los perros en el nuevo mundo no sabían ladrar, cuya fabulosa noticia se ha propagado hasta nuestros días, no faltando naturalistas que la hayan

18 Antonello Gerbi: La disputa del Nuevo Mundo. México: Fondo de Cultura Económica, 1993: 273. 
adoptado como un verdadero descubrimiento (Juan Ignacio Molina: Historia Geográfica, Natural y Civil del Reino de Chile: 1776: 302-303).

Las noticias sobre la variedad de animales, plantas y usos sociales diferentes, concita entre los naturalistas europeos reacciones que implican prejuicios y actitudes no siempre científicas. Recordemos sus problemas con la diversidad americana de camélidos u otros animales. Las historias de Clavijero, de Velasco y de Molina excedieron los criterios de la Real Academia española. Los procedimientos de éstos jesuitas o sus poéticas de la historia implicaron otra epistemología, más cercana al discurso de los hechos que a los hechos. La verdad de sus historias o su falsabilidad es indeterminable según sus prácticas científicas. Las historias de estos jesuitas, narran la mayoría de los usos y costumbres de la cultura azteca, andina y mapuche respectivamente, satisfaciendo incluso la posibilidad de lecturas diferenciadas. Estas noticias en prosa interesan no solo al lector simple, sino también "a las personas que gustan de las cosas Americanas", es decir, sus hermanos jesuitas dedicados a los estudios naturales y a los otros sabios europeos interesados en la diferencia.

Si para Gonzalo Fernández de Oviedo la Historia es ekfrasis, o sea una retórica ${ }^{19}$ de la descripción en su Historia general y Natural de las Indias (1535), para Juan de Velasco o para Molina la historia es autopsia (ver[se] con sus propios ojos, como criollos abogando por los americanos) y por extensión también teoría; un modo de ver, es decir conocimiento de una cultura particular. La infinidad de críticos que no han afrontado -por su carga eurocentrista- las propuestas étnicas y antropológicas que implican estas historias, igualmente no han sido ni serán capaces de reír con las "investigaciones" de De Paw sobre los americanos.

\section{La Historia civil de Molina}

El Compendio de la Historia Civil del Reyno de Chile de Molina, comparte con las historias anteriores el afán enciclopédico, una forma de narración más relacionada con la autopsia que con la retórica de la ekfrasis y la conciencia de que sus historias pertenecen a la Literatura. La narrativa de Molina se constituye como rerem gestarum (relato de hechos) frente al predominio de los hechos como criterio explicativo. Molina describe su escritura como "simple narración", no niega la gesta Dei como se desarrolla en Acosta, pero su historia tiene un objetivo menos moral que civil.

19 Juristas, teólogos y "filósofos, educados en el humanismo, se mostraron proclives a tratar los problemas americanos en forma retórica, con la intención de persuadir de la superioridad por naturaleza del hombre «civilizado» sobre el «bárbaro» cultural". Antonio Enrique Pérez Luño: La polémica sobre el Nuevo Mundo. Madrid: Trotta, 1995: 37. 
Las guerras [La Conquista y el Exilio de 1767] solo nos pueden suministrar materia digna de la historia en aquel país [Chile]. [...] Ninguna cosa afirmo que yo no la haya encontrado escrita entre los autores que me han precedido, o que no la haya adquirido de personas dignas de fe. Porque las reflexiones podían ponerme en compromiso, o hacerme comparecer más inclinado a una parte que a otra, he creído conveniente omitirlas, y limitarme a una simple narración ${ }^{20}$.

En el primer Compendio de la Historia Natural, Molina insiste en la narración y el orden referido:

hablo por grados, y pasando de las cosas más sencillas a las más compuestas [...] $\left.\right|^{\circ}$. de las aguas [...] $\|^{\circ}$ de las yerbas [...] $\mathrm{III}^{\circ}$ de los testáceos, de los crustáceos, de los insectos, reptiles, peces, pájaros, y de los cuadrúpedos singulares que he podido observar: concluyendo mi narrativa, formando una idea ligera del hombre, considerado como habitante de Chile, en cuyas montañas coloco igualmente los famosos patagones, reputados por gigantes de la especie humana, (J. I. Molina: obra citada: X-XI).

La Historia civil representa, ya no sólo la preocupación por la flora y fauna, sino la civilidad, el proceso que esos indígenas vivieron para superar el tránsito desde el estado salvaje al estado social. De cazadores a agricultores, de grupos nómades a comunidades establecidas, reguladas por normas y usos sociales, desarrollo que se vio obstaculizado por la irrupción del español:

se conoce todavía con mucha superficialidad un país tan apreciable, que no menos en la parte física que en la política presenta varios hechos dignos de consideración [...] de manera, que la índole, las costumbres y el armonioso lenguaje de sus antiguos habitantes, yacen tan ignorados como los maravillosos esfuerzos con que han procurado defender su libertad con tantas batallas como han dado desde el principio de la conquista hasta nuestros días (J. I. Molina: obra citada: V).

El paso de lo moral a lo civil, implica una concepción de progreso en la Historia, que tiene particulares expresiones en Molina:

20 Juan Ignacio Molina: Compendio de la Historia geográfica, natural y civil del Reyno de Chile. [Facsimilar. Primera parte] Madrid: Imprenta Antonio Sancha, 1788: Prefación del Autor: VI. 
se aboca al estudio de un solo país, Chile (que en su obra viene a representar toda América), y a partir de él construye un esquema de historia, válido para toda la humanidad, en el que los americanos aparecen ubicados en un estado intermedio de evolución, ya superado por las sociedades europeas. De este modo quiere afirmar que los pueblos americanos no son sociedades degeneradas, sino sociedades que han tenido un ritmo de progreso más lento ${ }^{21}$.

Podríamos asegurar -como hipótesis- que el Abate Molina coincide con Vico en su idea de historia, puesto que éste en la Ciencia nueva plantea las etapas de la historia de acuerdo al tiempo de lo Dioses, de los Héroes y de los Hombres, incluso en la importancia que da al lenguaje como depósito de todos los conocimientos, la Filología sería la articuladora de las Artes y las Ciencias. ${ }^{22}$

La etimología de las lenguas nativas es historia de las cosas significadas por estas palabras, siguiendo este orden natural de ideas: primero fueron las selvas, luego los campos cultivados y las chozas, después las casas pequeñas y las villas, de ahí la ciudad; y por último, las academias y los filósofos.

El historiador Mario Góngora, especialista en el periodo colonial, coincide con estas apreciaciones:

El chileno Juan Ignacio Molina defendió el clima y la fauna de su país de los ataques de Pauw, y probó, contrariamente a las declaraciones de Robertson, que los indígenas de Chile habían sido campesinos que usaban el azadón, y no simples cazadores. Este último punto era de gran importancia para Molina, puesto que él clasificaba las formas económicas de vida en una escala ascendente que incorpora básicamente un juicio de valor: la caza, el pastoreo, la agricultura, el comercio y la vida civilizada. Esta peculiar combinación entre un enfoque económico y juicios de valor, tanto políticos como morales, es típico en la actitud de los pensadores de la llustración respecto de la historia de la civilización, la que estaba presente en el núcleo de la visión del jesuita chileno ${ }^{23}$. naciones. [1725] [T. 1] Buenos Aires: Aguilar: 19602: 43.

23 Mario Góngora: Estudios sobre la historia colonial de Hispanoamérica. Santiago: Universitaria, 1998: 221. 
Sin embargo, otros jesuitas americanos exiliados, estarían igualmente en el caso descrito por Góngora. Sería el ejemplo de Velasco, de Clavijero, e incluso de Lacunza

[E]sos autores muestran una mucho mayor estima por las grandes culturas indígenas en el caso de algunas naciones, y en el caso de otras, admiración por la bravura militar de los indígenas hostiles, debido a su contribución al sentido de nacionalidad. Clavijero usa el término mexicano para los aztecas y lo hace igualmente para los habitantes contemporáneos de aquel país; y para Molina, las palabras chilenos y araucanos [aucas] son sinónimos; este uso implica una revolución en la comprensión de la historia, aun cuando esto nunca [...] se dijera explícitamente (Góngora 183).

De alguna forma, estas palabras de Molina -recibidas en clave progresista o regresiva- han figurado en muchos textos como evidencias de su opción política y simpatías por la independencia.

En la sucinta relación que hemos dado de los sucesos ocurridos en Chile después del descubrimiento del Nuevo Mundo, se ve que la posesión de este país ha costado a los españoles más sangre y más dinero que la del resto de la América (Molina HC 303).

\section{Conclusión}

El pensamiento de Molina sobre las comunidades aborígenes chilenas, implica la idea de desarrollo, los aucas, mapuches, es decir chilenos, habrían superado su etapa bárbara, de esta manera destruye la pretensión civilizadora de los soldados y de los encomenderos españoles, puesto que los mapuches ya tenían costumbres civiles. Su historia escrita se plantea como problema y es por tanto materia de indagación. Así inicia su Historia Civil:

El origen de los primeros habitantes de Chile se halla envuelto en densas tinieblas lo mismo que el de los demás americanos. No hay allí monumento que pueda en modo alguno esclarecer una investigación tan interesante. El uso de escribir, aquel arte maravilloso que nos hace presentes los siglos más remotos, era enteramente desconocido, cuando penetraron los europeos (Molina $\mathrm{HC} \mathrm{I}$ ). 
Luego acumula argumentos y pruebas para respaldar su hipótesis sobre la civilidad de los mapuches:

Estas menudencias [invenciones para pescar y cazar] no deberían quizá mencionarse en la exposición de las costumbres, e invenciones de un pueblo, que fuese conocido por algún mayor refinamiento en su cultura; pero en la historia de una nación incógnita, aislada, y considerada selvática, estas noticias se hacen apreciables, y aun necesarias para formar concepto del estado de sus progresos en la vida social (25)

Aunque los araucanos hayan salido mucho tiempo del estado salvaje, [...] se creen los solos que merecen el nombre de hombres sobre la tierra. De ahí es, que además del título de aucá, o libres, de que tanto se precian, se dan también por antonomasia, los nombres de che, o sea gentes [a los españoles] los llamaron huinca: esta perversa denominación, que con el uso y con el tiempo ha perdido su odiosidad, viene del verbo huincun, que significa asesinar [también] culme huinca, o miserables españoles (110-111).

Los usos civiles, es cierto no alcanzan para superar algunos problemas que Molina reseña, por ejemplo sobre las mujeres mapuches:

Además de las ocupaciones mujeriles, están ellas obligadas a aplicarse a muchas aquellas [trabajar la tierra por ejemplo] que en los países cultos son reservadas a los hombres, supuesto que, la máxima establecida entre todas las naciones bárbaras, el sexo débil ha nacido para la labor, y el fuerte para la guerra, y para el mando. Cada una debe todos los días presentar a su marido un plato aderezado, hecho por ella en su cocina o fogón (Molina HC 116).

A todo esto, Rojas Mix reclamaba un lugar de privilegio para el pensamiento y la historia de Molina en la cultura y el conocimiento latinoamericano, suscribo ese reclamo y aun más creo que falta estudio de su obra y de las Historias de esos sacerdotes americanistas y libertarios. Leyendo a Jacques Le Goff en el Prefacio al libro de su amigo Marc Bloch, se comprende aun mejor la posteridad de las ideas históricas del Abate.

Comprendamos bien a Marc Bloch. No dice: la historia es un arte, la historia es literatura. Si dice: la historia es una ciencia, pero una ciencia entre cuyas características puede estar su flaqueza pero también su virtud, que consiste en ser poética 
porque no se la puede reducir a abstracciones, a leyes, a estructuras. [...] exigía del historiador la conciencia de que el hecho histórico no es un dato "positivo", sino el producto de una construcción activa de su parte, para transformar la fuente en documento y luego constituir esos documentos y esos hechos históricos en problema ${ }^{24}$.

Sin embargo, la perspectiva que este trabajo pretendió desarrollar se planteó desde lo literario. La posibilidad de reconstruir o constatar una poética de la Historia en Molina, sería también una posibilidad en la mayoría de las Historias escritas por criollos, mestizos y americanos a partir del siglo dieciséis. Esto implicaría abordar esas narrativas [en sentido anacrónico] desde las particularidades que las definen como pertenecientes a un corpus y a un canon literario.

\section{Bibliografía}

Andrés abate, Juan: 1784. Origen, progresos y estado de toda la literatura. [Primera edición] Madrid: Antonio de Sancha, 1784.

Asúa, Miguel de: $1996 . \quad$ El árbol de las ciencias. Una historia del pensamiento científico. Bsa. As., Editorial FCE.

Beucheot, Mauricio: 1996 Historia de la filosofía en el México Colonial. Barcelona, Herder.

Blocj, Marc: 2003.

Apología para la historia o el oficio del historiador. México, Editorial FCE.

Capel, Horacio: 1944. "América en el nacimiento de la geografía moderna. O sea, de las crónicas medievales a las crónicas de Indias pasando por Plinio y el descubrimiento de las tierras nuevas". Suplemento Anthropos/ $43 \mathrm{La}$ geografía, hoy (Barcelona), 43, páginas42-51.

Jesús María Carrillo Castillo: 2004.

Naturaleza e imperio. L representación del mundo natural en la Historia general y natural de las Indias de Gonzalo Fernández de Oviedo. Madrid, Editorial Doce Calles

Darnton, Roberti: 1987. La gran matanza de gatos y otros episodios de la historia de la cultura francesa. México, Editorial FCE.

24 Marc Bloch: Apología para la historia o el oficio de historiador. México: Fondo de cultura económica, 2003²: 14-15. 
Gerbi, Antonello: 1993. La disputa del Nuevo Mundo. México, Editoral FCE.

Góngora, Mario: 1998. Estudios sobre la historia colonial de Hispanoamérica. Santiago, Editorial Universitaria.

Hachim, Lara, Luis: 2000. Tres estudios sobre el pensamiento crítico de la llustración americana. Alicante. Editan las universidades de Alicante y de Santiago de Chile.

Hachim Lara, Luis: 2003. "Sujeto y proyecto ilustrado en el Compendio de la Historia Geográfica, natural y Civil del Reybo de Chile (1776) del abate Juan Ignacio Molina", ponencia presentada en 2003 en Latin American Studies Association LASA, Dallas, Texas, March 2729

Howland Rowe, John: 1969. "Ethnografy and ethnology in the sixteenth century" The Krober Anthropoligical Society Papers University of California, Berkeley, 30 (Spring 1969).

Molina, Juan lugnacio: 2000. Compendio de la historia geográfica, natural y civil del Reyno de Chile [Facsimilar, primera parte] Santiago, Ediutorial Pehuén.

Molina, Juan Ignacio: $\quad$ Saggio sulla Storia Civile del Chili del Signor Abate Giovanni Ignacio Molina. Bologna Nella Stamperia de S. Tommaso dAquino. Con licenza de Superiori MDCCLXXXVII.

Montero Díaz, Santiago: 2005. "la doctrina de la historia de los tratadistas españoles del siglo de oro", Hispania (Revista española de historia. Madrid, IV (1941): 2-39.

Millones, Luis Domingo: 2005. El saber de los jesuitas, historias naturales y el Nuevo Mundo. Madrid, Vervuet/Iberoamericana.

Padgen, Anthony: 2004. "Presentación". Jesús M. Carrillo Castillo: Naturaleza e imperio. La representación del mundo natural en la Historia General y natural de las Indias de Gonzalo Fernández de Oviedo. Madrid: Doce Calles,

Rojas Mix, Miguel: 2001. El fin del milenio y el sentido de la historia. Santiago, Editorial Lom.

Vico, Giambattista: 1960. Principios de una ciencia nueva sobre la naturaleza común de las naciones (1725). Bs. As., Editorial Aguilar. 